\title{
Localization of fluconazole in oral cavity by preferential coating of buccoadhesive tablet for treatment of oral thrush
}

\author{
Kamla Pathak, Vijay Sharma, Nida Akhtar, Pragya Rastogi \\ Department of Pharmaceutics, Rajiv Academy for Pharmacy, Mathura, Uttar Pradesh, India
}

\begin{abstract}
Background: The present research work was aimed at localization of fluconazole in the oral cavity by preferential coating of buccoadhesive tablet for the treatment of oral thrush. Materials and Methods: In order to achieve the aim, buccoadhesive tablets were optimized using $3^{2}$ full factorial design to study the influence of varying content of chitosan and carbopol 934P (input variables) on the responses. Results: Perturbation plots revealed high sensitivity of the input variables to ex vivo mucoadhesion force and percent cumulative drug release (CDR) whereas the ex vivo mucoadhesion time was less sensitive to the input variables. Based on the highest desirability factor of 0.693 the formulation F9 was identified as the optimized formulation and was preferentially coated with ethyl cellulose $(3 \% \mathrm{w} / \mathrm{v})$ on one tablet face to get $\mathrm{F} 9 \mathrm{C}$. In reference to $\mathrm{F9}, \mathrm{F9C}$ showed superior mucoadhesive features $(P<0.05)$ but the \% CDR was comparable $\left(\mathrm{f}_{2}=\right.$ 50.80). The preferential coating (F9C, Jss $=0.812 \mu \mathrm{g} / \mathrm{cm}^{2} / \mathrm{h}$ ) limited the permeation of fluconazole across goat buccal mucosa by almost half the value of F9 (Jss $=1.34 \mu \mathrm{g} / \mathrm{cm} 2 / \mathrm{h}$ ) that could serve as an advantage in establishing high local concentration of drug in the oral cavity, thereby facilitating faster attainment of minimum inhibitory concentration. Scanning electron microscopy and histological analysis established nonirritant potential. The developed formulation was stable and demonstrated antifungal activity against Candida albicans. Conclusion: Thus it can be concluded that preferentially coated buccoadhesive tablets of fluconazole might be considered as a precise approach to localize the drug delivery in oral cavity.
\end{abstract}

Key words: Bioadhesive tablets, coated tablet, fluconazole, optimization, perturbation plots, preferentially localized delivery

\section{INTRODUCTION}

Oral thrush is a commensal fungal infection of the oral cavity and gastrointestinal tract in humans representing one of the major causes of mucosal and systemic infection. For the treatment of oral thrush, commonly used antifungal drugs are those which inhibit membrane component sterol synthesis (azoles, allylamines) and directly interact with the cell membrane or target cell wall

\section{Address for correspondence:}

Prof. Kamla Pathak,

Department of Pharmaceutics,

Rajiv Academy for Pharmacy, N. H. \#2,

Delhi-Mathura Road, P. O. Chhattikkara,

Mathura - 281 001, Uttar Pradesh, India.

E-mail: kamla_rap@yahoo.co.in

\begin{tabular}{|l|l|}
\hline \multicolumn{2}{|c|}{ Access this article online } \\
\hline Quick Response Code: & Website: \\
\hline & www.jpionline.org \\
\cline { 2 - 2 } & DOI: \\
\hline
\end{tabular}

synthesis. ${ }^{[1]}$ Fluconazole, an antifungal agent used clinically for the treatment of oral thrush, is commercially available as conventional tablets and capsules that offer poor bioavailability of the drug due to extensive hepatic first pass metabolism and gastric instability leading to frequent dosing. ${ }^{[2]}$ Thus, a formulation that can circumvent these limitations has been focus of the research on fluconazole.

Drug delivery by the buccal route can bypass the hepatic first pass effect and minimize the degradation in the gastric environment, thereby affecting enhancement in bioavailability and reduction

This is an open access article distributed under the terms of the Creative Commons Attribution-NonCommercial-ShareAlike 3.0 License, which allows others to remix, tweak, and build upon the work non-commercially, as long as the author is credited and the new creations are licensed under the identical terms.

For reprints contact: reprints@medknow.com

How to cite this article: Pathak K, Sharma V, Akhtar N, Rastogi $P$. Localization of fluconazole in oral cavity by preferential coating of buccoadhesive tablet for treatment of oral thrush. Int J Pharma Investig 2016;6:106-15. 
in total dose. Moreover, its $\log P$ value of 1 and its low molecular weight make it a suitable candidate for administration by the buccal route. ${ }^{[3]}$ Consequently, various research reports on buccal delivery of fluconazole can be found in literature. ${ }^{[4-8]}$ These research reports depicted large focus on the systemic delivery of fluconazole. However, a few claim the system(s) to be potentially useful for localized delivery of fluconazole for the treatment of oral thrush. While the claim cannot be overlooked, the authors of the present report would like to highlight few aspects of the delivery system. First, a buccoadhesive tablet/disc is capable of providing sustained release of fluconazole for permeation across buccal mucosa and simultaneously it may provide a local salivary concentration that may/ may not be sufficient to maintain minimum inhibitory concentration to kill the microorganism. Second, if a unidirectional system is designed to achieve maximum permeation across buccal mucosa, the localized delivery cannot be achieved to combat the infection. Thus, to achieve effective sustained salivary concentration, a buccoadhesive system that can ensure prolonged drug delivery of fluconazole in the oral cavity is desirable.

Preferentially coated buccoadhesive tablets were envisaged in the present study over already reported buccoadhesive tablets of fluconazole to provide localized delivery of the drug for the effective treatment of oral thrush with the objective to maintain the drug concentration in the mouth for prolonged period of time by unidirectional sustained release of drug toward the oral cavity. One-sided coating of the tablet with ethyl cellulose is expected to prevent the permeation of drug across buccal mucosa and hence its entry into the systemic circulation. For achieving the aim, buccoadhesive tablets of fluconazole were optimized using $3^{2}$ full factorial design followed by preferential coating of the optimized tablet and its evaluation.

\section{MATERIALS AND METHODS}

\section{Materials}

Fluconazole was obtained as a gift sample from Siemens Laboratories, Gurgaon, India. Other sources were carbopol 934P from Central Drug House (P) Limited, New Delhi, India; chitosan from S. Merck, India limited, New Delhi, India; talc from Ranbaxy fine chemicals limited, New Delhi, India; magnesium stearate, lactose, acetone, potassium dihydrogen orthophosphate and di-sodium hydrogen orthophosphate were procured from S. D fine chemical limited, Mumbai, India; ethyl cellulose was procured from Ray Chemicals (p) Ltd., Bangalore, India.

\section{Formulation design}

For optimization of buccoadhesive tablets, the amount of carbopol 934P and chitosan (independent variables) were varied. Each polymer was set at high, medium and low levels. A total of nine experimental formulations (F1-F9) were prepared in accordance to the $3^{2}$ full factorial design as shown in Table 1 . Fluconazole strength was kept constant at $50 \mathrm{mg}$ and the target weight of the tablet was fixed at $120 \mathrm{mg}$. The dependent variables were mucoadhesion time, mucoadhesion force and percent cumulative drug release (\% CDR). Additionally the tablets were evaluated for dimensions, hardness, weight uniformity, drug content, and swelling index (SI).

\section{Preparation of buccoadhesive tablets}

Direct compression method was used to formulate buccal tablets of fluconazole. Appropriate amount of drug (fluconazole) and excipients were weighed. The drug was thoroughly mixed in increasing magnitude of their weights with the ingredients except lubricant and glidant and intermixed for about $10 \mathrm{~min}$ in a distended polyethylene sac. Lubricant and glidant were added to the mixture of excipients prepared by uniform mixing and further all the excipients were mixed gently for $2 \mathrm{~min}$. The formulated blend was then subjected to compression using tablet punching machine.

\section{Evaluation}

\section{Weight variation}

Randomly selected 20 tablets were weighed individually, the average weight calculated and the individual tablet weight(s) was compared to the average weight. The difference in the percentage weight was calculated and assessed as per IP specifications. ${ }^{[9]}$ If not more than two tablets were found to be outside the percentage limit, and no tablet diverge by more than twice the percentage limit, the tablets followed IP limits.

\section{Hardness, diameter and thickness}

A vernier caliper (least count $=0.01$, Mitoyoto Corporation, Japan) was used to determine thickness and diameter of ten randomly selected tablets and the result expressed as mean

\begin{tabular}{|c|c|c|c|c|c|c|c|}
\hline Code & Fluconazole (mg) & Chitosan (mg) & Carbopol (mg) & Talc $(\mathrm{mg})$ & Magnesium stearate (mg) & Lactose (mg) & Dependent variables \\
\hline F1 & 50 & $25(\square 1)$ & $10(\square 1)$ & 1 & 1 & 33 & Ex vivo \\
\hline $\mathrm{F} 2$ & 50 & $35(0)$ & $10(\square 1)$ & 1 & 1 & 23 & mucoadhesion time \\
\hline F3 & 50 & $45(+1)$ & $10(\square 1)$ & 1 & 1 & 13 & $(\min )(\mathrm{Y} 1)$ \\
\hline F4 & 50 & $25(\square 1)$ & $15(0)$ & 1 & 1 & 28 & Ex vivo \\
\hline F5 & 50 & $35(0)$ & $15(0)$ & 1 & 1 & 18 & Mucoadhesion force \\
\hline F6 & 50 & $45(+1)$ & $15(0)$ & 1 & 1 & 8 & $(\min )(Y 2)$ \\
\hline F7 & 50 & $25(\square 1)$ & $20(+1)$ & 1 & 1 & 23 & Percentage of \\
\hline F8 & 50 & $35(0)$ & $20(+1)$ & 1 & 1 & 13 & $\mathrm{CDR}^{\mathrm{b}} \quad(\mathrm{Y} 3)$ \\
\hline F9 & 50 & $45(+1)$ & $20(+1)$ & 1 & 1 & 3 & \\
\hline $\mathrm{F} 10^{\mathrm{a}}$ & 50 & $30(\square)$ & $17.5(+0.5)$ & 1 & 1 & 20.5 & \\
\hline
\end{tabular}

${ }^{\mathrm{a}}$ Extra design check point, ${ }^{\mathrm{b}}$ Cumulative drug release 
values \pm standard deviation (SD). The hardness of the tablets was determined using Monsanto hardness tester and expressed in $\mathrm{kg} / \mathrm{cm}^{2}$. Three tablets were randomly picked from each formulation. Mean and SD values were calculated.

\section{Percent drug content}

Ten tablets were crushed and powder equivalent to $100 \mathrm{mg}$ of drug was homogenized with $10 \mathrm{ml}$ phosphate buffer, $\mathrm{pH} 6.8$ in a vortex mixer and filtered through whatmann filter. The resultant solution was suitably diluted with phosphate buffer, $\mathrm{pH} 6.8$ and analyzed spectrophotometrically at $261 \mathrm{~nm}$. The experiment was carried out in triplicate and average values reported.

\section{Swelling index}

Tablets $(n=3)$ were weighed individually (W1) and placed separately in Petri dishes containing $5 \mathrm{ml}$ of phosphate buffer, $\mathrm{pH}$ 6.8. At intervals of $1,2,4,8,10$, and $12 \mathrm{~h}$ the tablets were removed from the Petri dishes and excess surface buffer was removed carefully using the filter paper. The tablets (after swelling) were then weighed (W2) and SI was determined using the following equation:

$\mathrm{SI}=\mathrm{W} 2-\mathrm{W} 1 / \mathrm{W} 1$

Eq.1

\section{Ex vivo mucoadhesion time}

The ex vivo mucoadhesion time was evaluated by the method described by Han et al. ${ }^{[10]}$ Fresh goat buccal mucosa $(2 \mathrm{~cm} \times$ $2 \mathrm{~cm}$ ) was fixed in the inner side of the beaker, $2.5 \mathrm{~cm}$ away from the beaker bottom. One side of each tablet was wetted with $50 \mu \mathrm{l}$ of phosphate buffer, $\mathrm{pH} 6.8$ and adhered to the goat buccal mucosa by applying a light force with a fingertip for $20 \mathrm{~s}$. The beaker was filled with $200 \mathrm{ml}$ of phosphate buffer, $\mathrm{pH} 6.8$ maintained at $37 \pm 1^{\circ} \mathrm{C}$ and was stirred at $150 \mathrm{rpm}$. The time taken by the tablet to undergo segregation from buccal mucosa was measured and represented as the mucoadhesion time.

\section{EX vivo mucoadhesion force}

For measuring the ex vivo mucoadhesive strength of the tablets, the method described by Krishnarajan et al ${ }^{[11]}$ was

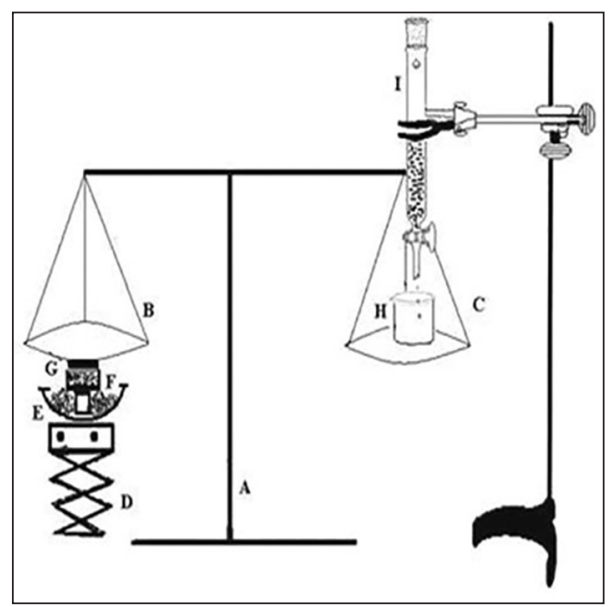

Figure 1: Assembly for measurement of in vitro mucoadhesive force (A) balance, (B) left pan, (C) right pan, (D) height adjusting pan, (E) water bath, $(F)$ sample holder, $(\mathrm{G})$ buccal mucosa, $(\mathrm{H})$ beaker, and $(\mathrm{I})$ burette used. The goat cheek pouch was removed. After washing, the excised pouch was adhered to the movable platform. The mucoadhesive tablet was clamped from one face to the steel piece with the help of cynoacrylate glue (used as an adhesive). The exposed tablet side was lubricated with $1 \mathrm{ml}$ of phosphate buffer, $\mathrm{pH} 6.8$ for $30 \mathrm{~s}$ to provide hydration and swelling initially. The platform was then raised upward until the hydrated tablet was brought into the contact with the mucosal surface [Figure 1]. A preload of $50 \mathrm{~g}$ was placed over the steel piece for $5 \mathrm{~min}$ as initial pressure to establish adhesion bonding between the tablet and goat buccal mucosa. After completion of the preload time, the preload was removed from the steel piece, and water was then added to the beaker from the burette at a constant rate drop by drop. The addition of water was stopped when the tablet detached from the goat buccal mucosa. The quantity of water (in terms of weight) needed to separate the tablet from buccal mucosa was observed and determined as mucoadhesive strength, and the experiments was conducted in triplicate using fresh buccal $(n=3)$. The mucoadhesive force was calculated according to the following equation:

Mucoadhesive force $(\mathrm{N})=\frac{\text { Mucoadhesive strength } \times 9.8}{1000}$

Eq. 2

\section{In vitro drug release}

A fabricated flow through apparatus [Figure 2] reported from our $\mathrm{lab}^{[12]}$ was employed to evaluate in vitro drug release to simulate continuous salivary secretion in the buccal cavity. The tablet was fixed on the glass slide with double adhesive tape and positioned in the test beaker at an angle of $60^{\circ}$. The release media (phosphate buffer, $\mathrm{pH}$ 6.8) was filled in the reservoir and allowed to fall on the tablet at a flow rate of $2 \mathrm{ml} / \mathrm{min}$. The media in the test beaker was stirred at $50 \mathrm{rpm}$ and maintained at $37 \pm 0.5^{\circ} \mathrm{C}$. A sample of $5 \mathrm{ml}$ was collected at predetermined time intervals from the collecting beaker and analyzed at $261 \mathrm{~nm}$ and reported as an average of three measurements $(n=3)$.

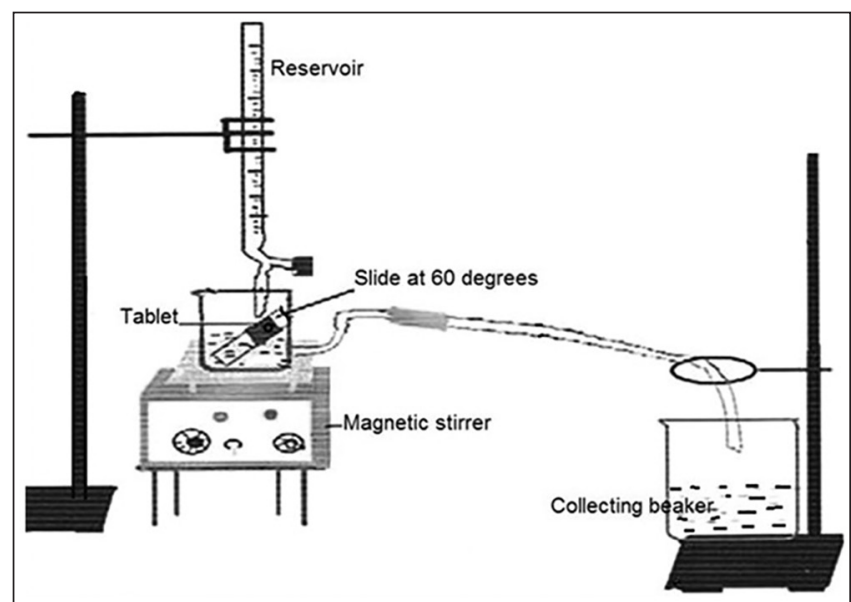

Figure 2: Diagrammatic representation of the modified flow through apparatus designed indigenously to study in vitro drug release from buccoadhesive formulations 


\section{Statistical analysis}

Design expert software version 9.0 (Stat-Ease, Inc, Minneapolis, USA) was employed for the evaluation of the influence of each independent variable on the desired response. One-way ANOVA was used for the analysis of each response coefficient for its statistical significance. To optimize and validate the statistical design, polynomial equations were developed. For validation, extra design checkpoint formulation (F10) was formulated and characterized for dependent responses. The experimental value(s) were compared with the predicted value(s) of the response(s) generated using polynomial equations. The experimental and predicted responses were compared using paired $t$-test at 95\% confidence interval $(P<0.05)$. The three-dimensional (3D) response surface graphs were developed to depict the concomitant effect of individual variable on each subsequent response parameter. The optimized formulation was selected on the basis of optimal response parameters and subjected to preferential coating.

\section{Tablet coating}

To achieve unidirectional drug release the optimized buccoadhesive tablet (F9) was subjected to preferential (onesided) coating. The buccoadhesive coating of optimized formulation was served by ethyl cellulose by dip coating method. For optimizing the coating strength, varied solutions (1, 2 and $3 \% \mathrm{w} / \mathrm{v})$ of ethyl cellulose in ethanol (95\% v/v) were used. Each tablet was gently held by forceps diametrically and carefully dipped into the coating solution, so that only one face of the tablet was dipped. The preferentially coated tablets were air dried for 30 min by storing the tablets in a manner that the tablet rested on its uncoated face.

\section{Evaluation of preferentially coated buccoadhesive tablet}

The preferentially coated buccoadhesive tablets were subjected to all the evaluation parameters described for buccoadhesive tablets in previous sections to select the best formulation. The selected formulation was subjected to some additional studies detailed in the preceding text, to describe functionality of the selected formulation.

\section{Scanning electron microscopy}

The photomicrograph of optimized preferentially coated buccoadhesive tablet (F9C) was obtained using scanning electron microscope (Leo Electron Microscopy Limited, Cambridge, England). Particles were coated with thin gold layer by sputter coater unit under an argon atmosphere to make them conductive. The coating time was 5-6 min. Surface morphology of both the sides was studied by the photomicrographs obtained at an acceleration voltage of $15 \mathrm{kV}$. The surface features were compared with uncoated buccoadhesive tablet (F9).

\section{Ex vivo permeation}

Ex vivo permeation studies were carried out to ascertain the permeability of drug using goat buccal mucosal membrane using fabricated Franz diffusion cell. The tissue was obtained from local slaughter house and stored in phosphate buffer, $\mathrm{pH}$ 6.8. The epithelium was detached from the underlined connective tissues with the help of surgical scissors and clenched between the donor and receiver compartments of the Franz diffusion cell to perform permeation studies. The receptor compartment contained $10 \mathrm{ml}$ of phosphate buffer, pH 6.8 stirred with a magnetic bead. The preferentially coated tablet (F9C) was placed on the mucosal surface in the donor compartment so that the coated side faced the permeation membrane. One milliliter of the sample was collected at different time points (from 0 to $8 \mathrm{~h}$ ) from the receptor chamber and fresh phosphate buffer, $\mathrm{pH} 6.8$ was added to perpetuate the sink conditions. The experiment was conducted by maintaining the temperature at $37 \pm 0.5^{\circ} \mathrm{C}$. The cumulative amount of drug permeated was analyzed by ultraviolet spectrophotometer $213 \mathrm{~nm}$. The experiment was repeated for $\mathrm{F} 9$ for the purpose of comparison.

\section{Histological evaluation}

Histological examination was also conducted to assess the toxic potential of the formulations using goat buccal mucosa as the model. Whole buccal mucosa of goat was collected from slaughter house and immediately transported to the laboratory in normal buffered saline in cold condition within $1 \mathrm{~h}$ of slaughtering. Buccal mucosa from excised mouth were immediately rinsed with isotonic sodium chloride solution $(0.9 \% \mathrm{w} / \mathrm{v})$ for $1 \mathrm{~min}$ and incubated for $30 \mathrm{~min}$ in the $\mathrm{F} 9 \mathrm{C}$ formulation at $37^{\circ} \mathrm{C}$, phosphate buffer saline (PBS), pH 6.8 as negative control and $75 \%$ isopropyl alcohol in PBS as positive control. The buccal mucosa was washed with PBS, pH 6.8 and immediately fixed with $10 \% \mathrm{v} / \mathrm{v}$ formalin solution for $24 \mathrm{~h}$. The mucosa was then dehydrated with ethyl alcohol gradient (70-100\%) and xylene, put in melted paraffin, and solidified in block forms. Then, cross sections $(<1 \mathrm{~mm})$ were made, mounted on glass slide and observed under microscopy for any histological changes after staining with hematoxylin and eosin for any histological damage if any.

\section{Stability}

Stability testing as per ICH Q1A (R2) ${ }^{[13]}$ guidelines were performed by storing the formulation $\mathrm{F} 9 \mathrm{C}$ in a sealed container at a temperature of $40 \pm 2{ }^{\circ} \mathrm{C}$ and humidity of $75 \pm 5 \%$ relative humidity. The samples were withdrawn at $0,30,60$, days and the weight gain/loss, ex vivo mucoadhesion force, ex vivo mucoadhesion time, and percent drug content were determined. The zero time samples were used as control.

\section{Antifungal activity}

The agar cup-plate method ${ }^{[9]}$ was used to assess the in vitro antifungal activity of G5 against Candida albicans. Thirty milliliters of sterilized nutrient agar media inoculated with microorganism ( $2 \mathrm{ml}$ of inoculum/100 $\mathrm{ml}$ of media) was poured into sterilized Petri plates. Three wells of diameter $5 \mathrm{~mm}$ were made via sterile borer in each Petri-plate. The formulation F9C and $0.2 \mathrm{ml}$ of standard (pure drug solution) were transferred to the cups aseptically. Negative control was also maintained. The plates were maintained at room temperature for $2 \mathrm{~h}$ and incubated at $28^{\circ} \mathrm{C}$ for $48 \mathrm{~h}$. The diameter of zone of inhibition surrounding each well was recorded. 


\section{RESULTS AND DISCUSSION}

\section{Buccoadhesive tablets}

Based on the literature survey, the mucoadhesive agents selected for the formulation of buccoadhesive tablets were chitosan and carbopol 934. Chitosan has been widely acclaimed as a mucoadhesive agent and reports on its formulation as hydrogels for the local release of a variety of drugs in the oral cavity including antifungal agents can be found. In addition to the released drugs, the chitosan polymer itself has shown antifungal activity. Chitosan hydrogels and films were able to limit adhesion of the common pathogen $C$. albicans to human buccal cells. ${ }^{[14]}$ Carbopol is yet another widely used bioadhesive excipient for fabrication of various pharmaceutical dosage forms. ${ }^{[15]}$ The buccoadhesive tablets of fluconazole were prepared by direct compression. The target weight of the tablets was set as $120 \mathrm{mg}$ so that the tablet is neither too big to appear as foreign object when placed in the buccal cavity nor it is too small to present difficulty in handling. The weight of prepared tablets (F1-F9) ranged between $119.60 \pm 0.35$ and $119.75 \pm 0.65 \mathrm{mg}$ [Table 2]. It was observed that not more than two tablets deviated from the average weight by more than $5 \%$ and none deviated more than twice of the average weight. This result was in accordance with the limits specified in IP. ${ }^{[9]}$ The tablets were sufficiently strong as the hardness of tablets varied from $3.86 \pm 0.11$ to $4.86 \pm 0.11$ $\mathrm{kg} / \mathrm{cm}^{2}$. The thickness of the tablets was in the range of $1.01 \pm$ 0.57 to $1.04 \pm 0.04 \mathrm{~mm}$ and the diameter was in between $4.03 \pm$ 0.001 and $4.045 \pm 0.001 \mathrm{~mm}$ [Table 2].

\section{Drug content and swelling index}

The drug content was found to vary from $91.07 \pm 1.1$ to 95.4. \pm $0.61 \%$ [Table 2]. Low value of SD indicated the drug content uniformity in all the formulations and was in good agreement with theoretical drug content. The SI of the formulations very narrowly ranged from $88.00 \pm 0.11$ to $89.64 \pm 0.14 \%$ [Table 2] suggesting that the varied levels of the polymers within the constraints of the design, did not affect the swelling attributes significantly.

\section{Ex vivo mucoadhesion time}

The ex vivo mucoadhesion time was found to be highest for F9 $(403.33 \pm 1.52 \mathrm{~min})$ and lowest for F1 [294.66 \pm 3.51 min; Table 2]. This parameter was affected by the levels of mucoadhesive polymers. Categorically, the ex vivo mucoadhesive time increased with increasing concentration of carbopol. Thus, formulations F1-F3 made with lowest levels of carbopol demonstrated lower values of ex vivo mucoadhesion time that those made with highest level of carbopol (F6-F9). Further, for a given level of carbopol an increase in chitosan concentration led to increased ex vivo mucoadhesion thus describing an augmented effect of using two mucoadhesive polymers. Frequently, the literature cites use of a combination of mucoadhesive polymers for achieving desired mucoadhesion. ${ }^{[16,17]}$

\section{Ex vivo mucoadhesive force}

The ex vivo mucoadhesive force values of the buccoadhesive tablets ranged between 0.019 and $0.056 \mathrm{~N}$ [Table 2] and the values obtained followed the same pattern as that of ex vivo mucoadhesion time. Correspondingly, an increase in mucoadhesive force was observed on increasing carbopol levels and for a given concentration of carbopol the mucoadhesive force increased with increasing chitosan concentration. The highest ex vivo mucoadhesive force obtained in case of formulation F9 $(0.056 \pm 0.002 \mathrm{~N})$ could be attributed to highest levels of both carbopol $934 \mathrm{P}$ as well as chitosan. Increase in mucoadhesive force with increase in amount of chitosan and carbopol was observed because of the hydrophilic groups: Carboxylic group, and hydroxyl group present in the polymer, that can strongly bind to oligosaccharide chain present in buccal mucus membrane resulting in a strong bioadhesive force. ${ }^{[18]}$

\section{In vitro drug release}

The comparative in vitro drug release profiles of the formulation F1-F9 [Figure 3] revealed sustained release of fluconazole from the buccoadhesive tablets. For a given level of carbopol, an increase in chitosan concentration increased the drug release. This may be attributed to the loosening of network within the buccoadhesive

\begin{tabular}{|c|c|c|c|c|c|c|c|c|c|}
\hline Code & $\begin{array}{c}\text { Average } \\
\text { weight } \\
\text { (mg) }\end{array}$ & $\begin{array}{l}\text { Thickness } \\
(\mathrm{mm})\end{array}$ & $\begin{array}{l}\text { Hardness } \\
\left(\mathrm{kg} / \mathrm{cm}^{2}\right)\end{array}$ & $\begin{array}{l}\text { Percentage } \\
\text { of swelling } \\
\text { index (12 h) }\end{array}$ & $\begin{array}{c}\text { Percentage } \\
\text { of drug } \\
\text { content }\end{array}$ & $\begin{array}{c}\text { Ex vivo } \\
\text { mucoadhesion } \\
\text { time (min) }\end{array}$ & $\begin{array}{c}\text { Ex vivo } \\
\text { mucoadhesive } \\
\text { force }(\mathrm{N})\end{array}$ & $\% \mathrm{CDR}_{12 \mathrm{~h}}$ & $\begin{array}{l}\text { Desirability } \\
\text { factor }\end{array}$ \\
\hline $\mathrm{F} 1$ & $119.6 \pm 0.75$ & $1.04 \pm 0.004$ & $4.16 \pm 0.28$ & $89.12 \pm 0.02$ & $91.72 \pm 1.10$ & $294.66 \pm 3.51$ & $0.019 \pm 0.005$ & $80.82 \pm 1.35$ & 0.091 \\
\hline F2 & $119.6 \pm 0.67$ & $1.03 \pm 0.042$ & $3.86 \pm 0.11$ & $89.31 \pm 0.18$ & $92.43 \pm 0.61$ & $340.33 \pm 2.51$ & $0.029 \pm 0.003$ & $83.65 \pm 1.23$ & 0.383 \\
\hline F3 & $118.7 \pm 0.65$ & $1.04 \pm 0.002$ & $3.93 \pm 0.11$ & $89.64 \pm 0.14$ & $93.61 \pm 0.56$ & $347.33 \pm 1.52$ & $0.049 \pm 0.003$ & $95.08 \pm 1.30$ & 0.431 \\
\hline F4 & $119.6 \pm 0.67$ & $1.04 \pm 0.006$ & $4.64 \pm 0.17$ & $89.25 \pm 0.13$ & $91.47 \pm 1.95$ & $333.33 \pm 2.51$ & $0.021 \pm 0.002$ & $80.68 \pm 1.31$ & 0.405 \\
\hline F5 & $119.8 \pm 0.65$ & $1.04 \pm 0.004$ & $4.77 \pm 0.17$ & $89.56 \pm 0.07$ & $93.49 \pm 0.77$ & $361.33 \pm 1.52$ & $0.032 \pm 0.002$ & $85.91 \pm 1.29$ & 0.537 \\
\hline F6 & $119.7 \pm 0.65$ & $1.02 \pm 0.004$ & $4.53 \pm 0.46$ & $88.16 \pm 0.11$ & $95.61 \pm 0.55$ & $371.33 \pm 1.51$ & $0.052 \pm 0.001$ & $92.89 \pm 1.35$ & 0.681 \\
\hline F7 & $119.7 \pm 0.65$ & $1.01 \pm 0.008$ & $4.86 \pm 0.11$ & $88.09 \pm 0.07$ & $92.71 \pm 0.76$ & $373.33 \pm 3.05$ & $0.022 \pm 0.001$ & $82.87 \pm 1.20$ & 0.506 \\
\hline F8 & $119.7 \pm 0.67$ & $1.01 \pm 0.008$ & $4.83 \pm 0.28$ & $88.16 \pm 0.16$ & $95.47 \pm 0.61$ & $380.43 \pm 2.51$ & $0.031 \pm 0.002$ & $87.63 \pm 1.10$ & 0.620 \\
\hline F9 & $119.7 \pm 0.73$ & $1.01 \pm 0.057$ & $4.86 \pm 0.11$ & $88.72 \pm 0.02$ & $94.13 \pm 0.96$ & $403.33 \pm 1.52$ & $0.056 \pm 0.002$ & $90.59 \pm 2.53$ & 0.693 \\
\hline
\end{tabular}

CDR: Cumulative drug release 


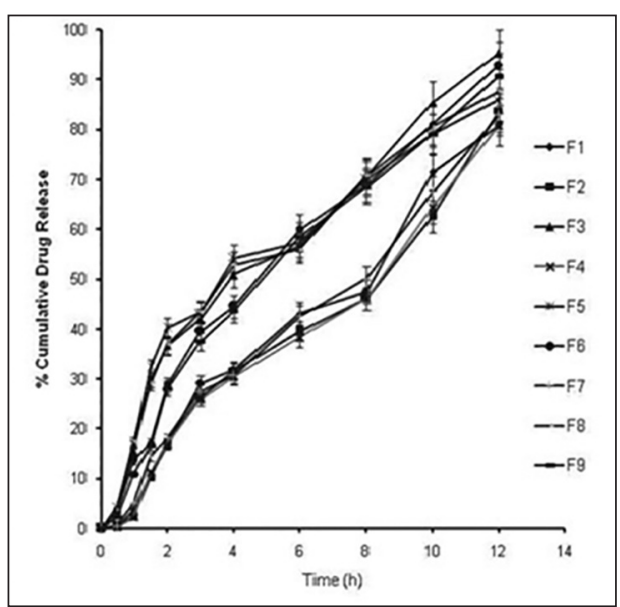

Figure 3: Percent cumulative in vitro drug release profiles of buccoadhesive formulations (F1-F9) in phosphate buffer, $\mathrm{pH} 6.8$

tablet with consequent ease of penetration of release medium and diffusion of drug from the matrix. On the other hand, increasing the levels of carbopol displayed a retarding effect. The polymer retarded the drug release due to increase in the tortuosity as a result of swelling of polymer in contact with aqueous fluid that increases the path length available for drug to diffuse out from the swollen matrix. ${ }^{[19]}$ Hence, the drug release was interplay of combinatorial effect of bioadhesive polymer chitosan and gel forming property of carbopol 934P. While six formulations displayed incomplete drug release of $<90 \%$, formulations F3, F6 and F9 with CDR of $95.08,92.89$ and $90.59 \%$ respectively were compared. The order of drug release was F3 $>$ F6 $>$ F9 and the release data best fitted Higuchi kinetics $\left(R^{2}=0.972-0.975\right)$. The value of $n$ was $>0.5$ (F3:0.504; F6:0.525; F9:0.513) but $<1$ indicating diffusion as the mechanism of drug release ${ }^{[20]}$ from the formulations.

\section{Optimization}

On the basis of data for dependent variables, a general statistical model can be developed and characterized by polynomial equation using Design expert software version 9.0 (Stat- Ease, Minneapolis, USA Inc.). After omitting the nonsignificant coefficients by application of one-way ANOVA, the final reduced (transformed) equations for the observed responses are as follows:

Ex vivo mucoadhesion time $(\mathrm{Y} 1)=360.22+18 \mathrm{X}_{1}+19.83 \mathrm{X}_{2}+$ $20.66 \mathrm{X}_{1} \mathrm{X}_{2}-23.66 \mathrm{X}_{1} \mathrm{X}_{2}^{2}$

Ex vivo mucoadhesion force $(\mathrm{Y} 2)=0.0306+0.0158 \mathrm{X}_{1}+$ $0.0058 \mathrm{X}_{2}$

$\% \mathrm{CDR}_{12 \mathrm{~h}}(\mathrm{Y} 3)=85.71+5.70 \mathrm{X}_{1}+1.972 \mathrm{X}_{2}-1.64 \mathrm{X}_{1} \mathrm{X}_{2}+$ $1.43 \mathrm{X}_{1}^{2}-2.58 \mathrm{X}_{1}^{2} \mathrm{X}_{2}$ Eq.5

In the above equations, coefficients with more than one factor represents the interaction between factors, while coefficients with second order terms indicate the quantitative effect of independent variables (X1 and $\mathrm{X} 2$ ) on the responses (Y1, Y2, and Y3). From these polynomial equations, response surface graphs of the respective responses were generated, which were then used to predict the responses of dependent variables at the intermediate levels of independent variables.

The 3D response surface graph for ex vivo mucoadhesion time [Figure 4a] was a complex curvilinear profile showing maximum mucoadhesion time when both X1 and X2 were at highest level. On the other hand, the 3D response graph for ex vivo mucoadhesion force [Figure 4b] showed an almost linear relationship between $\mathrm{X} 1, \mathrm{X} 2$ and $\mathrm{Y} 2$. Hence on increasing the amount of chitosan and carbopol 934P a corresponding increase in $\mathrm{Y} 2$ was observed. This may attribute to the bioadhesive property of chitosan and carbopol 934P polymer, because of which they uptake water and adhere to the buccal mucosa. Thus at the highest sum total concentration of polymers maximum mucoadhesive force was observed in formulation F9. The response graph for percent CDR [Figure 4c] was nonlinear $3 \mathrm{D}$ curve that explained the simultaneous effect of X1 and X2 on Y3. An increase in the level of chitosan and a decrease in levels of carbopol favored drug release. When both were at highest level the possible reason for reduction in the total release of drug may be due to the interaction between two oppositely charged bioadhesive polymers. The cationic chitosan and the anionic carbopol, may form an inter polymer complex that may result in retardation of the dissolution rate. ${ }^{[21]}$ To further visualize the response surface a special form of response plot called "perturbation" for response surface methods data were generated. Perturbation plots help to compare the effect of all the factors at a particular point in the response surface methodology design space. The response is plotted by changing only one factor over its range, while holding all other factors constant. By default, design-expert sets the reference point at the midpoint (coded 0 ) of all of the factors. In a perturbation plot, a steep slope or curvature in an input variable indicates a relatively high sensitivity of response. ${ }^{[22]}$ Accordingly, the sensitivity of ex vivo mucoadhesion time was poor to the levels of polymers chitosan and carbopol [Figure 5a] and on the other hand, both the responses: Ex vivo mucoadhesion force [Figure 5b] and \% CDR [Figure 5c] were highly sensitive to the input variables. Hence on the basis of the responses formulation F9 was selected as the optimized formulations.

\section{Validation of the experimental design}

The experimental design was validated by preparing an extra design checkpoint formulation F10. The polynomial equations generated were utilized for calculating the predicted values of ex vivo mucoadhesion time, ex vivo mucoadhesion force and \% CDR. The close resemblance between predicted and experimental value ascertained the validity of experimental design. Low values of percentage error [Table 3] between predicted and experimental values affirmed the prognostic ability of the design.

\section{Tablet coating Single side coated buccoadhesive tablet}

Biaoadhesive formulations not only modulate the drug delivery, but they also immobilize the formulations on the mucosa at best site for activity. It has been demonstrated that the dosage forms 


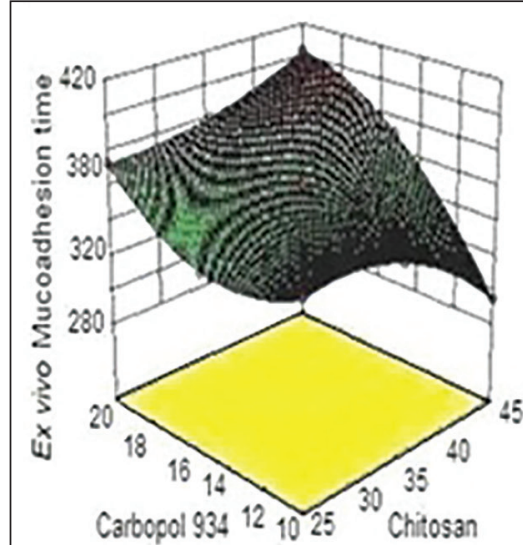

(A)

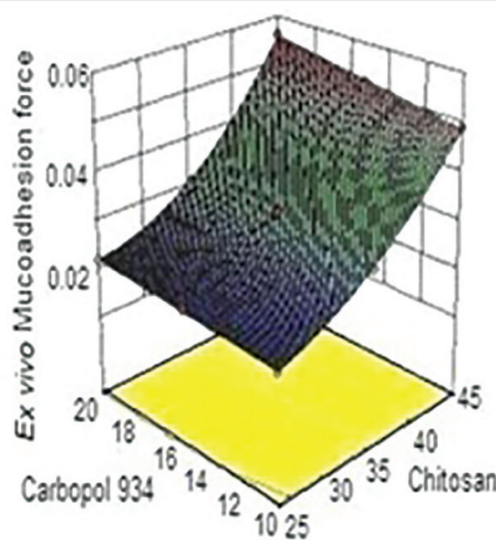

(B)

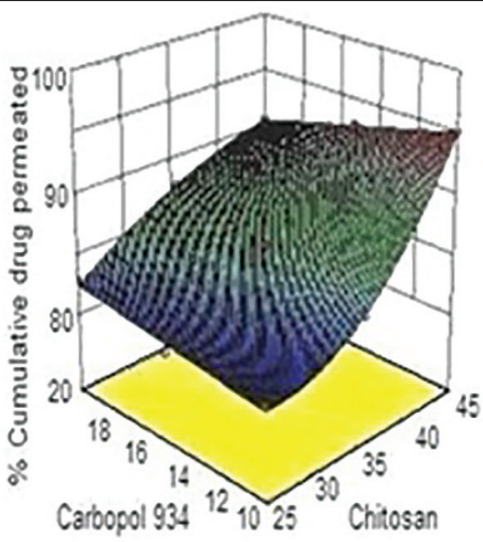

(C)

Figure 4: Three-dimensional surface response plots depicting the effect of varying concentration of chitosan and carbopol on (a) ex vivo mucoadhesion time, (b) ex vivo mucoadhesion force, and (c) \% cumulative drug release

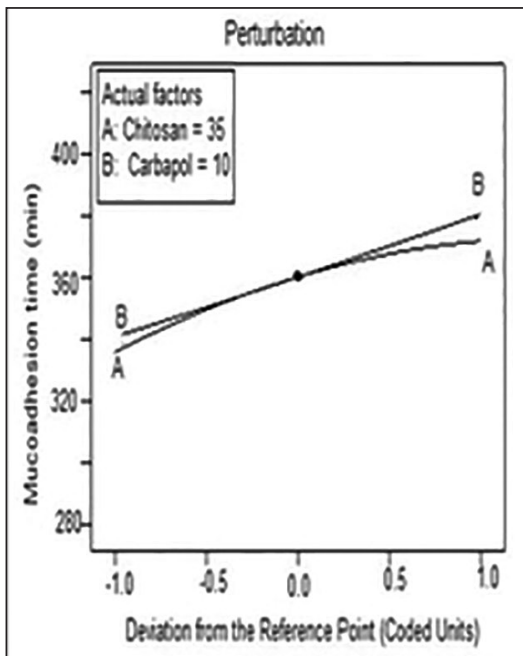

(A)

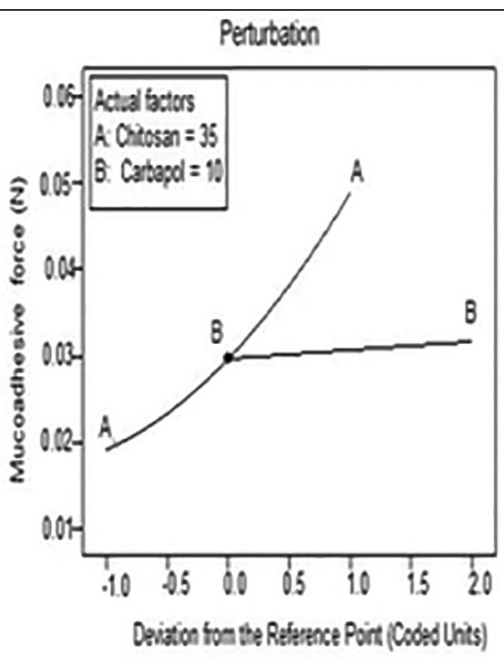

(B)

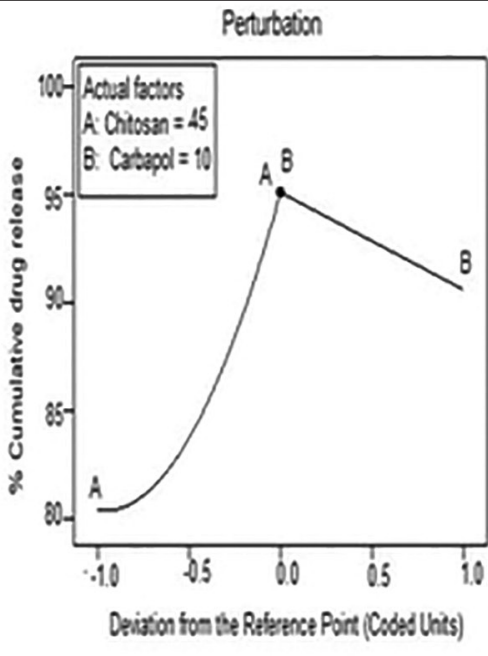

(C)

Figure 5: Perturbation plots to analyze the sensitivity of the responses to the input variables (a) ex vivo mucoadhesion time, (b) ex vivo mucoadhesive force, (c) \% cumulative drug release

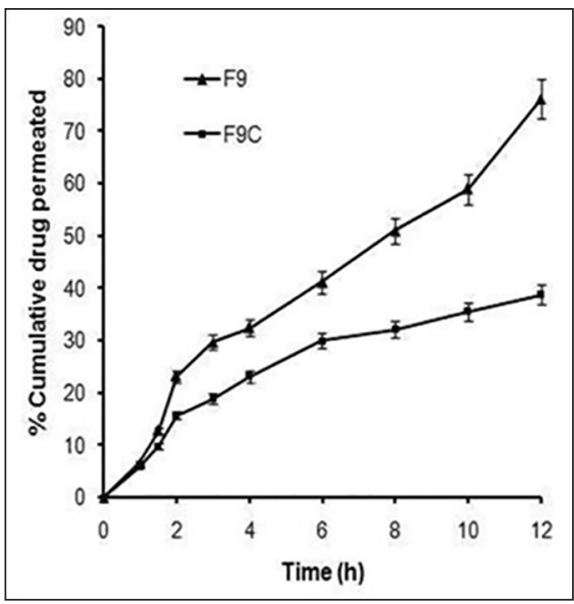

Figure 6: Ex vivo permeation profiles of $\mathrm{F9}$ and $\mathrm{F9C}$ across goat buccal mucosa containing cellulosic polymers (hydroxypropyl methylcellulose [HPMC], EC) have bioadhesive properties with respect to esophageal and gastrointestinal mucosa. The optimized buccoadhesive tablet (F9) was preferentially coated with $3 \% \mathrm{w} / \mathrm{v}$ coating solution of ethyl cellulose. Ethylcellulose was selected as coating polymer for the following reasons,

1. It is tasteless,

2. Is GRAS listed and recommended safe for oral formulations,

3. Recommended as a coating agent and

4. Is bioadhesive though its bioadhesive capacity is less than carbopol and chitosan.

In a study conducted by Bagul et al., ${ }^{[23]}$ on determination of in vitro mucoadhesive strength of polymers for mucoadhesive drug delivery system, the authors reported the following ascending order for force of adhesion (N). Gelatin (1.42) < 
gum dammar $(1.47)<$ gum copal $(1.52)<$ ethyl cellulose $(1.60)$ $<$ sodium alginate $(1.71)<$ xanthan gum $(1.81)<$ chitosan (1.91) < HPMC (2.25), carbopol (2.40). While gelatin and carbopol showed lowest and highest mucoadhesive strength respectively, ethyl cellulose displayed intermediate force of adhesion. Hence was selected for the preferential coating of the optimized bioadhesive tablet F9. Three different strengths of ethyl cellulose solutions were screened for preferential coating. The coating strength of $3 \% \mathrm{w} / \mathrm{v}$ resulted in appropriately coated tablet that was labeled as F9C and evaluated.

\section{Evaluation}

\section{Physicochemical characteristics}

The average weight of the preferentially coated tablets (F9C) was found to be $119.98 \pm 0.96 \mathrm{mg}$ that was marginally $(0.23 \%)$ higher than uncoated tablet. It was observed that not more than two tablets deviated from the average weight by more than $5 \%$ and none deviated more than twice of the average weight. This result was in accordance with the limits specified in $\mathrm{IP}^{[9]}$ The hardness of tablets was measured as $4.93 \pm 0.28 \mathrm{~kg} / \mathrm{cm}^{2}(1.4 \%$ more than F9), the thickness of the tablets was $1.12 \pm 0.14 \mathrm{~mm}$ $(0.11 \%$ more than F9) and the diameter was observed to be $4.040 \pm 0.08 \mathrm{~mm}$. Marginal increase recorded in hardness and thickness of F9C was attributable to the preferential coating by ethyl cellulose. The drug content was determined as $95.72 \pm$ $0.96 \%$. Low value of SD indicated uniformity of the drug content and was in good agreement with the theoretical drug content.

\section{Ex vivo mucoadhesion time and mucoadhesion force} The ex vivo mucoadhesion time of F9C was found to be $429.33 \pm$ $2.64 \mathrm{~min}$ that was significantly $(P<0.05)$ more than the optimized formulation F9 [Table 4]. The bioadhesive coating provided greater surface area because of the fine deposits of ethyl cellulose particles on the tablet surface owing to which the uptake of water was facilitated and hence adhered to the mucosa for longer time than F9. The mucoadhesive force of F9C was also significantly higher $(P<0.05)$ as compared to that of $\mathrm{F} 9$ [Table 4]. The results also assessed the ability of buccoadhesive tablets coated with ethyl cellulose to serve the purpose of adherence similar to F9.

\section{In vitro drug release}

The $\%$ CDR in $12 \mathrm{~h}$ from F9C was found to be $88.63 \pm 3.76 \%$ which was lower than that from F9 $(90.59 \pm 2.51 \%)$ but was nonsignificantly $(P>0.05)$ different than F9. To confirm the similarity in release profiles, similarity factor (f2) was calculated. The $\mathrm{f} 2$ value of 50.80 implied similarity between the two release profiles. ${ }^{[24]}$ The release data of F9C best fitted Higuchi model kinetics with $r^{2}$ value of 0.9685 and $n=0.522$ specified the drug release to be diffusion controlled. Clearly, preferential coating with ethyl cellulose did not affect the release profile of the drug and at the same time it offered superior mucoadhesion characteristics.

\section{Ex vivo permeation}

The purpose of carrying out the study was to assess the ability of coating to hinder permeation of drug across the buccal mucosa when applied to the buccal surface on its coated side. The ex vivo permeation study of F9C showed $38.78 \%$ cumulative drug permeation (CDP) in $12 \mathrm{~h}$ through goat buccal mucosa in comparison to $76.24 \% \mathrm{CDP}$ from F9 in $12 \mathrm{~h}$ [Figure 6]. The $\% \mathrm{CDP}$ decreased to almost half the value of F9 (significantly different; $P<0.01)$. The steady state flux of F9C was calculated as $0.812 \mu \mathrm{g} / \mathrm{cm}^{2} / \mathrm{h}$ in comparison to $1.34 \mu \mathrm{g} / \mathrm{cm}^{2} / \mathrm{h}$ of F9. The reduction in permeation is attributed to the fact that coating of ethyl cellulose on F9C limited the permeation of fluconazole across goat buccal mucosa. This could serve as an advantage as less permeation across mucosa will help in establishing high local concentration of drug in the oral cavity thereby facilitating faster attainment of minimum inhibitory concentration.

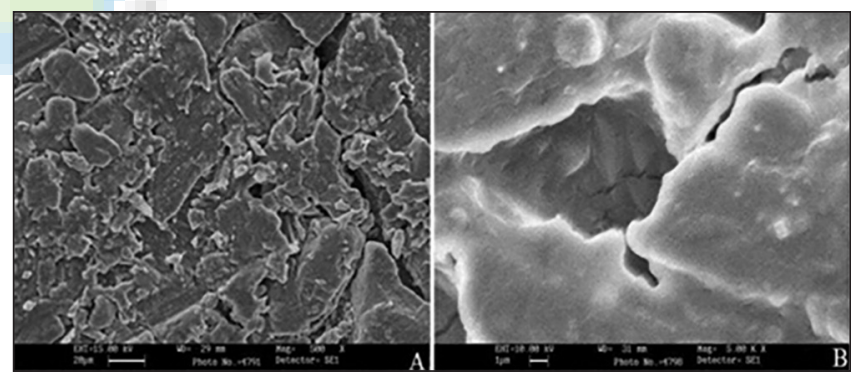

Figure 7: Scanning electron micrographs of (a) uncoated surface and (b) coated surface of F9C

Table 3: Comparison of predicted and experimental data of extra design check point formulation (F10)

\begin{tabular}{lccc}
\hline Response & Predicted value & Experimental value & Percentage error \\
\hline Ex vivo mucoadhesion time $(\mathrm{min})$ & 351.19 & 350.33 & 0.244 \\
Ex vivo mucoadhesion force $(\mathrm{N})$ & 0.035 & 0.033 & 5.71 \\
${\text { Percentage of } \mathrm{CDR}_{12 \mathrm{~h}}}$ & 84.28 & 83.94 & 0.403 \\
\hline
\end{tabular}

CDR: Cumulative drug release

\begin{tabular}{|c|c|c|c|}
\hline Formulation code & Ex vivo mucoadhesive time (min) & Ex vivo mucoadhesive force (N) & $\mathrm{CDR}_{12 \mathrm{~h}}(\%)$ \\
\hline $\begin{array}{l}\text { F9 (optimized uncoated) } \\
\text { F9C (preferentially coated bioadhesive tablet) }\end{array}$ & $\begin{array}{l}403.33 \pm 1.52 \\
429.33 \pm 2.64\end{array}$ & $\begin{array}{l}0.056 \pm 0.002 \\
0.069 \pm 0.005\end{array}$ & $\begin{array}{l}90.59 \pm 2.51 \\
88.63 \pm 3.76\end{array}$ \\
\hline
\end{tabular}

CDR: Cumulative drug release 


\section{Scanning electron microscopy}

Scanning electron microscopy was used to visualize the morphology of the coated surface of F9C and compared it to the uncoated surface so as to assess the impact of coating on the tablet surface. Scanning electron microscopy image of the uncoated surface [Figure 7a] showed fine cracks/fissures, jointed flattened irregular shaped particles of varied shapes as a result of the compression forces of tablet punches. The coated surface on the other hand presented smoother surface view free of cracks/ depressions and clearly depicting the folds of coated material [Figure 7b]. The smoothened coated surface presented irritation free dosage form.

\section{Histological evaluation}

The effect of F9C on the structural integrity of goat buccal mucosa was evaluated to assess histological damage if any to the buccal mucosa in reference to appropriate controls. Treatment with uncoated tablet surface did not show any destructive effect on buccal mucosa epithelium and the mucosal integrity was maintained [Figure 8a]. Incubation with isopropyl alcohol (positive control) [Figure 8b] resulted in widening of narrow intercellular spaces with deformation and distortion of superficial epithelial cells. The results of treatment with coated tablet surface [Figure 8c] of the formulation F9C were similar to both the treatment with uncoated surface, and negative control [Figure 8d]. Neither cell necrosis nor any damage was observed. Thus, formulation F9C was appeared to be safe with respect to buccal administration.

\section{Stability}

The stability data of F9C has been summarized in Table 5. As indicated that there was no significant difference in average weight, percent drug content, mucoadhesion force and time before and after storage of the formulation up to 60 days. This dictated good stability of the formulation upon storage.

\section{Antifungal activity}

The zone of inhibition by F9C measured $9.7 \pm 0.15 \mathrm{~mm}$ that was less than zone of inhibition produced by standard solution $(10.6 \pm 0.37 \mathrm{~mm})$. On applying Student's $t$-test $(P<0.05)$ at $95 \%$ confidence interval, no significant difference in the antifungal activity was observed. Thus, the antifungal activity of fluconazole was not affected by its incorporation in the developed formulation.

\section{CONCLUSIONS}

The preferentially coated bioadhesive tablets of fluconazole were successfully developed. One-sided coating of the optimized tablet resulted in a tablet that exhibited sufficient mucoadhesion and limited permeation of drug across buccal mucosa. This would help in establishing high local concentration of drug in the oral cavity thereby facilitating faster attainment of minimum inhibitory concentration for treatment of oral thrush. Development of preferentially coated buccoadhesive tablets of

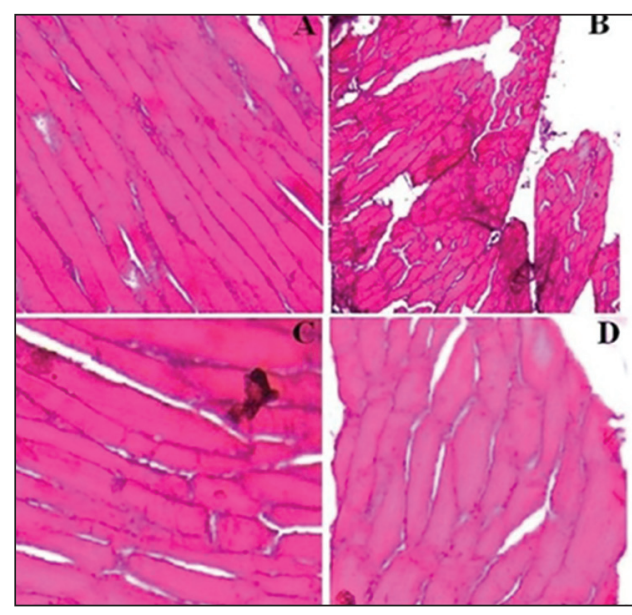

Figure 8: Histological images of goat buccal mucosa, stained with hematoxylin-eosin after incubation with (a) F9, (b) $75 \%$ isopropyl alcohol (positive control), (c) F9C, and (d) phosphate buffer saline, pH 6.8 (negative control)

\begin{tabular}{lcccc} 
Table 5: Stability data of F9C \\
\hline $\begin{array}{l}\text { Time } \\
\text { (days) }\end{array}$ & \multicolumn{4}{c}{ Parameter } \\
\cline { 2 - 5 } & $\begin{array}{c}\text { Average } \\
\text { weight } \\
\text { mg } \pm \text { SE }\end{array}$ & $\begin{array}{c}\text { Drug } \\
\text { content } \\
\text { (\%) }\end{array}$ & $\begin{array}{c}\text { Ex vivo } \\
\text { mucoadhesion } \\
\text { force (N) }\end{array}$ & $\begin{array}{c}\text { Ex vivo } \\
\text { mucoadhesion } \\
\text { time (min) }\end{array}$ \\
\hline 0 & $119.98 \pm 0.96$ & $95.72 \pm 0.96$ & $0.069 \pm 0.005$ & $429.33 \pm 2.64$ \\
30 & $119.6 \pm 0.89$ & $94.06 \pm 0.47$ & $0.055 \pm 0.003$ & $422.33 \pm 3.26$ \\
60 & $119.5 \pm 0.72$ & $94.13 \pm 0.94$ & $0.057 \pm 0.005$ & $404.33 \pm 2.48$ \\
\hline
\end{tabular}

SE: Standard error

fluconazole can be considered as a precise approach to localize the drug delivery in oral cavity.

Financial support and sponsorship

Nil.

\section{Conflicts of interest}

There are no conflicts of interest.

\section{REFERENCES}

1. Williams D, Lewis M. Pathogenesis and treatment of oral candidosis. J Oral Microbiol 2011;3:57-71.

2. Correa JC, Salgado HR. Review of fluconazole properties and analytical methods for its determination. Crit Rev Anal Chem 2011;41:124-32.

3. Kushwaha S, Sharma PK, Bansal M. Development and evaluation of buccal adhesive fluconazole tablets. Asian J Pharm Biol Res. 2011;1:195-200.

4. Yehia SA, El-Gazayerly ON, Basalious EB. Design and in vitrol in vivo evaluation of novel mucoadhesive buccal discs of an antifungal drug: Relationship between swelling, erosion, and drug release. AAPS PharmSciTech 2008;9:1207-17.

5. Mohamed SP, Muzzammil S, Pramod KT. Preparation of fluconazole buccal tablet and influence of formulation expedients on its properties. Yao Xue Xue Bao 2011;46:460-5.

6. Yehia SA, El-Gazayerly ON, Basalious EB. Fluconazole mucoadhesive buccal films: In vitrolin vivo performance. Curr Drug Deliv 2009;6:17-27. 
7. Thipparthi RT, Dhanaraj KS, Mohd AB, Sajeeth $\mathrm{Cl}$. Buccoadhesive drug delivery system of fluconazole inclusion complex. Int J Res Pharm Biomed Sci 2011;2:765-75.

8. Maheshwara RC, Firoz S, Rajalakshmi R, Kumar AC. Formulation and evaluation of oral thermorevesible in situ gel containing fluconazole. Int J Pharm Res Anal. 2011;1:15-20.

9. Indian Pharmacopoeia; Indian Pharmacopoeial Commission, Ministry of Health and Family Welfare. Ghaziabad, India; 2007.

10. Han RY, Fang JY, Sung KC, Hu OY. Mucoadhesive buccal disks for novel nalbuphine prodrug controlled delivery: Effect of formulation variables on drug release and mucoadhesive performance. Int J Pharm 1999;177:201-9.

11. Krishnarajan D, Kumar SN, Kanikanti S. In-vitro and ex-vivo evaluation of mucoadhesive tablets using natural polymers by gastro retentive drug delivery system. Indo Am J Pharm Res 2014;4:445-50.

12. Patel A, Kumar M, Bali V, Pathak K. Comparative evaluation of porous versus nonporous mucoadhesive films as buccal delivery system of glibenclamide. AAPS PharmSciTech 2013;14:1321-32.

13. Available from: http://www.fda.gov/downloads/drugs/ guidancecomplianceregulatoryinformation/guidances/ ucm073369.pd [Last accessed on 2015 Jan].

14. Bhattarai N, Gunn J, Zhang M. Chitosan-based hydrogels for controlled, localized drug delivery. Adv Drug Deliv Rev 2010;62:83-99.

15. Fu J, Sun X, Zhang ZR. Study on of bioadhesive property of carbomer 934 by a gamma camera in vivo. World J Gastroenterol 2002;8:176-9.
16. Martinac A, Filipovic-Grcic J, Voinovich D, Perissutti B Franceschinis E. Development and bioadhesive properties of chitosan-ethylcellulose microspheres for nasal delivery. Int J Pharm 2005;291:69-77.

17. Semalty A, Semalty M, Nautiyal U. Formulation and evaluation of mucoadhesive buccal films of enalapril maleate. Indian J Pharm Sci 2010;72:571-5.

18. Devrajan PV, Adani MH. Oral Transmucosal Drug Delivery. In: Jain NK. Editor. Controlled Drug Delivery System. Vol. 1. New Delhi: CBS Publishers and Distributors; 2002. p. 52-81.

19. Sogias IA, Williams AC, Khutoryanskiy VV. Chitosan-based mucoadhesive tablets for oral delivery of ibuprofen. Int J Pharm 2012;436:602-10

20. Sakthivel M, Kannan K, Manavalan R, Senthamasai R. Formulation and in vitro evaluation of noisome containing oxcarbazepine. Int J Pharm Sci 2012;4:563-7.

21. Desai KG, Kumar TM. Preparation and evaluation of a novel buccal adhesive system. AAPS PharmSciTech 2004;5:e35.

22. statease.info [homepage on the Internet]. Mineapolis: Section 12: Statistical Details- Analysis [updated 2001 October 7]. Available from: http://www.statease.info/dx6files/manual/DX11Details-Design.pdf [Last accessed on 2015 Jan].

23. Bagul U, Gujar K, Dhat S, Aphale S, Bhavsar M. In vitro study of mucoadhesive strength of polymers for mucoadhesive drug delivery systems. Int J Curr Pharm Res 2009;1:42-6.

24. Costa P, Sousa Lobo JM. Modeling and comparison of dissolution profiles. Eur J Pharm Sci 2001;13:123-33. 